\title{
'NOVOS PRODUTOS' COMO COMPETÊNCIA DO ADVOGADO
}

Gilberto de Abreu Sodré Carvalho

'NEW PRODUCTS' AS A LAWYER'S COMPETENCE

\section{RESUMO}

A PARTICIPAÇÃO PROFISSIONAL DO ADVOGADO EM PROJETOS DE "NOVOS PRODUTOS" TEM SIDO COMUM HÁ MUITO TEMPO NO Brasil. Entretanto, nÃo SE sabe da FORMulação de QUALQUER TÉCNICA DE ACEITAÇÃO GERAL PARA A CONTRIBUIC̣ÃO DO AdVOgado. Este ARTIgo, DENTRO dA TEMÁtICA 'DIREITO \& GESTÃo', VISA OFERECER UMA POSSÍVEL METODOLOGIA PARA PROJETOS DE NOVOS PRODUTOS EM QUE O ADVOGADO TENHA PAPEL PROTAGONISTA. NESSA METOdOLOgIA, O TERMO PROPOSTO "PRÉ-PRODUTO" COMPORTA A IDÉIA DE UM OBJETO SENDO MODELADO DE ACORDO COM SUA ADAPTAÇÃO A SISTEMAS AMBIENTAIS SOB ESTRUTURANTES JURÍDICAS ATÉ QUE SE TORNE UM PRODUTO A SER LANÇADO.

\section{PALAVRAS-CHAVE}

NOVOS PRODUTOS, METODOLOGIA, 'DIREITO \& GESTÄO', AMBIENTES JURÍDICOS, CURRÍCULO ACADÊMICO

\section{ABSTRACT}

COUNSEL'S PROFESSIONAL PARTICIPATION IN 'NEW PRODUCTS' PROJECTS HAS BEEN SEEN FOR A LONG TIME, IN BRAZIL. HOWEVER, TO OUR KNOWLEDGE, NO GENERALLY ACCEPTED TECHNIQUE FOR COUNSEL'S CONTRIBUTION THERETO HAS BEEN DEVELOPED YET. THIS ARTICLE IN THE FIELD OF 'LAW \& MANAGEMENT' AIMS AT PROVIDING A POSSIBLE NEW PRODUCTS PROJECT METHODOLOGY IN WHICH COUNSEL IS ASSIGNED A PROTAGONIST ROLE. IN SUCH METHODOLOGY THE COINED TERM 'PRE-PRODUCT' SHOWS THE IDEA OF AN OBJECT BEING MODELED IN ACCORDANCE WITH ITS ADAPTATION TO SEVERAL LEGAL STRUCTURED ENVIRONMENT SYSTEMS UNTIL IT BECOMES A PRODUCT TO BE LAUNCHED.

\section{KEYWORDS}

NEW PRODUCTS, METHODOLOGY, 'LAW \& MANAGEMENT', LEGAL ENVIRONMENTS, LAW SCHOOL CURRICULUM

\section{INTRODUÇÃO}

O objetivo deste artigo é a formulação de uma metodologia básica que possa ser usada por advogados em projetos de "novo produto" ou "novo serviço" de mercado, sabendo-se que "produto" e "serviço" se correspondem um ao outro como conceitos, uma vez que ambos apresentam repetitividade e de padronização; dizer 'novos produtos' corresponde a dizer 'novos produtos e serviços' (CARVALHO, 2003, p. 21).

Este estudo dirige-se aos advogados que atendam questões não-judiciais em organizações empresariais, organizações governamentais e organizações não-governamentais e sejam chamados a participar da projetação e da validação de novidades em geral a serem 
dirigidas ao público consumidor, no sentido mercadológico, ou aos públicos-alvo das organizações governamentais e não-governamentais.

No contexto deste artigo, teremos como referência a organização empresarial, no entanto, o mesmo pode servir de rascunho para os dois outros tipos de organização, em que como novidade se poderia ter um novo tributo a ser cobrado, um serviço federal de coleta de material radioativo e eletrônico, isto é, qualquer novidade (inovação) a ser colocada a um público determinável.

Insere-se este texto no âmbito temático de Law \& Management ou Direito \& Gestão. Nesse plano, o conteúdo apresentado sugere investigação sobre os "translimites" ou as áreas sombreadas entre as contribuições dos gestores e consultores de marketing perante o advogado organizacional.

Existem diversos trabalhos que se endereçam aos profissionais de gestão sobre novos produtos e seus projetos, como, entre vários, os de Urban e Hauser (1993) e Cooper (2001). Nas escolas de Administração e Marketing, a temática de novos produtos é tratada, já nas escolas de Direito isso não ocorre. Assim, sem qualquer prévio preparo formal, advogados têm ingressado nesse campo por força da realidade que determina formidavelmente a condicionante jurídica. É sabido que há mais de meio século as empresas, em especial as de origem norte-americana, no Brasil, têm feito o advogado interno ou de escritório participar de projetos de novos produtos. Desde há muito, os advogados têm tido seu papel reconhecido e inafastável. As exceções existiram em empresas nacionais típicas e nas de origem européia, estas menos afeitas ao papel do advogado em projetos de novos produtos. Hoje, aceita-se no Brasil como regra a participação do profissional jurídico, ainda que falte - fora das normas internas das grandes corporações - um modelo de atuação de aceitação geral. Mais ainda: não existe um modelo que seja desenhado a partir da ótica própria do profissional jurídico, ou seja, algo metodologicamente seu. As tinturas passadas nos cursos de especialização que tocam o tema "novos produtos", nas escolas de Marketing ou Administração, tendem (por evidente) a dar peso ao assessoramento do advogado, e não a reconhecer a intervenção verdadeiramente protagonista do profissional jurídico.

Em regra, o advogado posto frente a frente a "novos produtos" demora a adquirir maturidade técnica, o que só se dá com muita experiência. Percebe-se que estaria na graduação o tempo para se apropriar do território da competência do advogado, de certos espaços de investigação transdisciplinar, entre esses novos produtos. Seria como uma marcação de território e uma autopercepção do estudante como alguém a se desenvolver para projetos do novo, em que o Direito é condicionante, e não só cuidar de situações de confronto, como se tem no contencioso e na condução de saídas para problemas jurídicos dentro da dogmática do Direito. É ainda dominante a idéia de que cabe ao advogado analisar, sob a dogmática legal, o já ocorrido ou mapear as questões mediante o modelo do certo ou errado ou do 
verdadeiro ou falso, estabelecendo situações de contradição entre dois pólos, como: isto é e aquilo não é, ou seja, visualizando oposições ou situações adversárias. É verdade que as novas escolas de Direito da Fundação Getulio Vargas, em São Paulo e no Rio de Janeiro, buscam desenvolver intencionalmente nos alunos capacitação proativa na formulação ou design de soluções. No entanto, trata-se de experiência recente, com pouca repercussão.

O modo tradicional de perceber a função do advogado é, apenas e ainda, adequado para a atividade do contencioso judicial ou administrativo ou para a elaboração de pareceres a consultas especificamente no plano jurídico. No entanto, não serve para o fazimento do novo ou para a inovação. Não é afeito a projetar-se ou criar-se a novidade, quando não há registros de conhecimento que possam dar imediata sustentação a dizer-se que algo é certo ou errado, verdadeiro ou falso. Na gestação do novo, ele pode alterar-se para atender a ditames restritores e a receber forma e conteúdo para aproveitar espaços. Trata-se da modelagem de algo que se vai descobrindo. Não é trabalho analítico de alguma coisa existente, mas de perceber alguma coisa a ainda existir (DE BONO, 1991). Como pano de fundo, tem-se que os advogados brasileiros estão sendo crescentemente exigidos pelos seus clientes a serem criativos e inovadores dentro de uma economia global formidavelmente competitiva que se volta às exigências do conhecimento aplicado e da criatividade.

Em suma, o que os advogados têm a oferecer a seus clientes é aprendido fora da escola, nos escritórios e nas organizações. ”Novos produtos“ é um exemplo da defasagem entre o modelo acadêmico-curricular de graduação e as exigências profissionais de décadas. Outros exemplos podem ser: relações organizações-governos; planejamento estratégico; inteligência competitiva; e gestão de proteção da propriedade imaterial. Esses são tópicos ao acesso transdisciplinar dos profissionais do Direito.

Este artigo é, isto posto, uma contribuição à discussão e definição de uma metodologia profissional do advogado em projetos de novos produtos dentro das organizações empresariais. É ainda, esperamos, o oferecimento público de um novo olhar sobre um papel do advogado que tem sido escondido até aqui: o advogado como designer do novo, como um profissional de criação.

\section{SUGESTÃO DE UM MODELO DE ATUAÇÃO PROFISSIONAL}

Parece-nos que o acesso investigativo jurídico nos projetos de novos produtos, em seguida a obra doutrinária seminal de Leães (1987), legitimou-se por força do Código de Defesa do Consumidor. Este estabelece nos artigos 12 e 14, e no conjunto do seu texto, que o fornecedor responde pelo seu produto independentemente de culpa pela reparação dos danos causados aos consumidores por defeitos decorrentes 
de projeto, fabricação, construção, montagem, fórmulas, manipulação, apresentação, acondicionamento e informações insuficientes ou inadequadas sobre sua utilização e riscos. O artigo 12 se reporta a produtos e o 14, a serviços; tratam, no fundo, do mesmo objeto, uma vez que produto e serviço se identificam, como tratado antes neste artigo.

Outro ponto a legitimar o acesso investigativo jurídico é a emergência do Direito Concorrencial, visto em termos amplos, o qual aponta para o dever de o fornecedor de produtos respeitar a livre concorrência e ser leal nos seus procedimentos perante os demais fornecedores do mercado relevante em que seus produtos disputem a escolha dos consumidores (CARVALHO, 2002).

Tudo isso ocorre em situação básica na qual os valores, princípios e regras de Direito Constitucional, Direito Administrativo, Direito Tributário, Direito do Trabalho, Direito da Propriedade Industrial e outros são condicionantes e modeladores de novos produtos. Importa dizer que novos produtos, como objeto de conhecimento, é tema profissional jurídico, tanto quanto é assunto de Marketing, de Engenharia da Produção, de Pesquisa e Desenvolvimento ou de Gestão de Projetos. Cabe lembrar o ensaio de Fernando Gherardini Santos (2000), em que se identificou um "Direito do Marketing", tendo o marketing como objeto próprio da investigação jurídica.

Um projeto de novo produto é uma tarefa criativa à base de tentativas e erros, uma vez que, ao mesmo tempo em que segue um curso de procedimentos, reinventa, em revisões constantes, seu próprio objeto de investigação. Não se visa aqui a apresentação de uma "receita de bolo" ou de uma metodologia que faça dar certo - sob o ponto de vista jurídico e geral -, se seguidos passos específicos. Trata-se apenas de uma metodologia desenvolvida na nossa experiência profissional. O que se quer é provocar, com base em uma techne artesanal, a discussão de uma metodologia consistente para todos ou, ainda, se for o caso, aperfeiçoar-se o aqui apresentado.

$\mathrm{O}$ advogado pode e deve ter um modelo validado que o ajude nos projetos de novos produtos. A consultoria jurídica organizacional brasileira no início do século XXI está definitivamente comprometida com o design ou a modelagem de soluções, e não apenas com a saída jurídica "mágica" ou a intervenção corretiva. Essa percepção do advogado como um criador ou um designer faz resultar a conveniência da imposição de algum método profissional que venha a ser geralmente aceito. Deve estar voltado, assumimos, à visão transdisciplinar a partir do Direito (ver em específico: CARVALHO, 2003; CARVALHO; CAVALCANTI, 2007; e, no geral, quanto à transdisciplinaridade: NICOLESCU, 2001; DOMINGUES, 2005) ou para o lateral thinking (DE BONO, 1992) que determine caminhos mesmo que aparentemente fora da matéria jurídica, mas dirigidos à proteção jurídica do produto.

Na nossa ótica, o ponto a desenvolver para que fique evidente o papel do advogado nos projetos de novos produtos é o "estudo dos ambientes", em que se torna 
mandatória a atitude transdisciplinar, a competência de interface com outras áreas do conhecimento e razoável cultura geral. Transdisciplinaridade, conforme Nicolescu (2001, p. 50-52), “como o prefixo 'trans' indica, diz respeito àquilo que está ao mesmo tempo entre as disciplinas, através das diferentes disciplinas e além de qualquer disciplina. Seu objetivo é a compreensão do mundo presente, para o qual um dos imperativos é a unidade do conhecimento". "Pensamento lateral" ou lateral thinking (DE BONO, 1992) significa o uso de caminhos não-padronizados ou não-focais na procura do novo. Em verdade, uma coisa é resolver um problema como um puzzle, outra é conceber ou desenhar o novo.

No estudo dos ambientes, implicações jurídicas e ”transjurídicas” podem surgir de qualquer ponto em que o produto em projeto esteja presente após seu lançamento. Em nosso modelo metodológico, tais ambientes são estruturados por elementos jurídicos. O papel estruturante dos elementos jurídicos corresponde ao conceito de "paradigma', como se tem em Kuhn (2003), quando esse autor explica o modo da validação do que é correto cientificamente e o que não é, dentro de determinada circunscrição do conhecimento e determinado momento da História da Ciência. No caso presente, remetemos ao termo para indicar que os elementos jurídicos têm papel estruturante em cada ambiente onde o produto estará. A função paradigmático-estruturante, ou seja, modeladora dos elementos jurídicos no âmago dos sistemas ambientais, se cumpre por via de essas dimensões corresponderem, em cada caso, a valores, assunções, princípios e regras que dão ordem ou coerência à nossa cognição do dado ambiente. Em outras palavras, a adequada interpretação dos ambientes ocorrerá com o uso das estruturantes jurídicas.

\section{O PRÉ-PRODUTO}

Chamamos de "pré-produto" um futuro ou possível produto sendo estudado (e enquanto estiver sendo estudado), isto é, ainda no papel, na bancada ou no monitor de computador. Nossa metodologia é da construção, no sentido mais amplo, do novo produto por via das percepções sobre o "pré-produto" vis-à-vis os ambientes. Cabe projetar o novo produto, por via de permanentes revisões e acertos no "pré-produto", em decorrência das informações extraídas do seu comportamento perante aspectos ambientais em situação de laboratório. Nessas inúmeras situações, o "pré-produto" estará “oportunizado" (ou seja, o aspecto ambiental estudado responde de forma sinergética ou, ao menos, favorável), "estará viável” (ou seja, o aspecto ambiental analisado ao mesmo tempo não oferece resistência, mas não corresponde à oportunidade especial), estará “ameaçado” (ou seja, o aspecto ambiental investigado responde negativamente, ainda que sem clareza ou certeza de rejeição), ou estará "bloqueado" (ou seja, o aspecto ambiental investigado obstrui ou barra o "pré-produto"). A identificação das interações ambientais, 
as quais adaptamos e desenvolvemos, tem origem na Universidade de Harvard, na década de 1970, sendo conhecida como a matriz SWOT (strenghts, weaknesses, opportunities e threats). Sobre o assunto, entre outros, se tem Thompson e Strickland III (2002).

Vamos supor que exista uma encomenda de estudos sobre a viabilidade de um produto, ou seja, de um "pré-produto", feita por iniciativa do gestor de organização empresarial a quem se atenda. Em vista da encomenda, terão de ser desenvolvidas as indicações iniciais do gestor em termos de formulação conceitual do "pré-produto" e testar sua consistência perante o ambiente ou suas segmentações operativas (ambientes), até que se chegue ao "pré-produto" final, que constará de projeto executivo na forma de um plano, ao mesmo tempo amplo e detalhado, de todas as atividades de produção e entrega. Em outras palavras, o trabalho do projeto é ser sistemicamente orientado, com o "pré-produto" visto como uma 'criatura' a existir em ambiente de laboratório, como um "animal engenheirado geneticamente" que se testa e possa, uma vez completo seu projeto, inserir-se na ecologia já preparado para superar ou fugir de predadores e adversidades, buscar alimento, procriar e sobreviver por um dado ciclo de tempo.

\section{AMBIENTES DE PRÉ-PRODUTO}

Por ambientes entendemos as segmentações temáticas do ambiente pleno do “pré-produto”. Cada ambiente é, assim, o conjunto de oportunidades, viabilizações, ameaças e bloqueios de dado tipo que se apresenta para o "pré-produto", em antecipação laboratorial ao que se apresentaria em situação real para o novo produto. O "pré-produto" deve ser validado em todos os ambientes. Deve afirmar-se por inteiro garantindo a previsão de retorno financeiro que lhe tenha sido fixada, sem embaraços imprevistos. Esse resultado ideal é o que se espera do projeto executivo.

Por certo, a Ciência do Direito, em sua estrutura dogmática, não tem por objeto esses temas. Trata-se de assunto tecnológico sustentado transdisciplinarmente (seria um tema jurídico "zetético", como referido em FERRAZ JUNIOR, 2001, 44-47), no campo do que se pode chamar de Law \& Management, na falta de melhor enquadramento. Como em Drucker (1993, p. 10-20), a tecnologia, no sentido aqui usado, é a techne submetida à sistematização como conhecimento recolhido, logia. No caso, a techne do advogado sobre novos produtos é obtida na lida com seus clientes.

Na teoria das organizações, Lawrence e Lorsch (1967) estão entre os que primeiro perceberam a importância do ambiente na modelagem das organizações e, por extensão, podemos assumi-la na modelagem de novos produtos como técnica, como pretendido neste trabalho. De rigor, o ambiente corresponde a uma continuidade de 
elementos em interação e é uno. No entanto, para fins práticos, isto é, de conhecimento aplicado, podem-se identificar vários ambientes de investigação. A decomposição anunciadado ambiente em diversos ambientes é um procedimento que se tem de algum modo já em Lawrence e Lorsch (1967) e visa dar condições à investigação organizada, independentemente de virmos em seguida a proceder à aproximação sistêmica como em Bertalanffy (2001). Os ambientes são sistemas sob estruturantes jurídicas, os quais formam um sistema ambiental maior. A decomposição é útil para efeito de método.

Identificamos oito ambientes pela decomposição do ambiente real, percebendose que nossa segmentação desconsidera diferenças entre ambientes imediatos e macroambientes, uma vez que essa diferenciação não teria proveito para o propósito deste trabalho. Os ambientes são: ambiente jurídico-político (o mais 'jurídico' dos ambientes, sem que os demais percam essa referência), ambiente interno, ambiente cultural, ambiente socioeconômico, ambiente científico-tecnológico, ambiente concorrencial, ambiente do consumidor e ambiente espaço-tempo.

Vamos a cada um deles, explicando seus conteúdos e mostrando suas "estruturantes jurídicas”, isto é, condicionantes jurídicas (valores, princípios e regras jurídicas) que organizam sistemicamente o entendimento dos ambientes.

\section{OS AMBIENTES UM A UM}

\section{I Ambiente Jurídico-Político}

Corresponde ao ambiente das interações do "pré-produto" com as oportunidades, viabilidades, ameaças e bloqueios feitos pelas legislações do Brasil e/ou, conforme o caso, dos países onde o "pré-produto" venha a ser comercializado. Inclui as barreiras e restrições da tributação e as oportunidades de incentivos fiscais e financeiros. Compreende as regras de Direito Constitucional, Regulatório, Civil, Comercial, Administrativo, do Trabalho, Previdênciário, do Consumidor e de Propriedade Industrial que incidam sobre o "pré-produto". Cabe verificar se o "pré-produto" resiste a esse ambiente e como tirar proveito dele. Se o não provocar o retorno financeiro esperado por conta das ameaças e dos bloqueios desse ambiente, é o momento de abandoná-lo, pondere-se.

\section{I. I ESTRUTURANTES JURÍDICAS}

O sistema jurídico no conjunto e na especificidade de suas normas afeta diretamente o "pré-produto". Essas normas são de Direito Constitucional, Direito Administrativo, Direito Tributário, Direito do Trabalho, Direito Obrigacional e dos Contratos, Direito Societário, Direito Civil, Direito Comercial e Direito Penal. Os valores, princípios e regras jurídicas da generalidade da ordem jurídica são os elementos (estruturantes e demais) deste sistema ambiental. 


\subsection{Ambiente InTerno}

Corresponde às interações do "pré-produto" com as oportunidades, viabilidades, ameaças e bloqueios que se apresentem a ele quanto à disponibilidade de condições e meios de fábrica, recursos humanos, insumos em geral, distribuição de recursos econômicos e financeiros. Nesse ambiente, o "pré-produto" terá de disputar oportunidade com outros possíveis pré-produtos e produtos existentes. Além de ser um ambiente em que parece haver objetividade quanto à coleta de dados para análise, é também altamente politizado (MORGAN, 2002, p. 177-214), isto é, os gerentes de outros projetos, ou seja, de outros pré-produtos e de produtos, estarão disputando os mesmos recursos e os mesmos meios. É uma questão, muitas vezes, de definição política ou de vontade política do gestor em direcionar os recursos e meios para o “pré-produto", e não para outros fins. Evidentemente, se não houver a garantia dos recursos e meios internos, cabe alterar o "pré-produto" ou deixá-lo de lado para melhores tempos.

\subsection{ESTRUTURANTES JURÍdicas}

As questões relativas a orçamento e planejamento são objeto de decisões normativas pelos órgãos próprios da organização empresarial. Nesse quadro, serão necessárias providências de Direito Societário para a legitimação da provisão de recursos para o “pré-produto”. Os valores, princípios e regras jurídicas societárias são os elementos estruturantes deste sistema ambiental.

\subsection{Ambiente Cultural}

Esse ambiente corresponde às interações do "pré-produto" com as oportunidades, viabilidades, ameaças e bloqueios que se podem apresentar a ele perante os valores e ideais prestigiados pela comunidade em que o "pré-produto" será comercializado. Também se incluem como elementos desse ambiente os hábitos, preceitos religiosos ou filosóficos praticados, noções de felicidade, prazer e interesses intelectuais, formas de mostrar consideração social, meios de aquisição de prestígio social e perda de prestígio, gosto estético, noção do certo e do errado e tudo o mais que representar modelo mental. Caso o "pré-produto" não satisfaça ou não se harmonize com o ambiente cultural, caberá reformulá-lo ou alterá-lo no que for ameaçado ou bloqueado, em favor de sua viabilização ou mesmo oportunização. Se a adaptação for impossível, deve-se examinar se o projeto criativo não deve ser terminado, esquecendo-se por ora ao menos do "pré-produto".

\subsection{Estruturantes Jurídicas}

A Constituição Federal protege o livre-arbítrio e as manifestações culturais e religiosas, bem como não admite preconceitos injustos, por qualquer razão que seja. Nesse quadro, abre oportunidade para ações de danos morais para os ofendidos. Os valo- 
res, princípios e regras jurídicas constitucionais protetivas do ser humano e da sua dignidade são os elementos estruturantes deste sistema ambiental.

\section{4·4 Ambiente Socioeconômico}

Corresponde às interações do "pré-produto" com suas oportunidades, viabilidades, ameaças e bloqueios no tocante à comunidade ou ao suposto mercado-alvo do "pré-produto", relativas a demografia, perfis sociais e distribuição da renda, efetividade e modo da movimentação social. Esse ambiente importa ao "pré-produto" quanto ao público-alvo e ao retorno de preço que o mercado estaria disposto a pagar por ele. Se o preço possível for insuficiente para um retorno financeiro satisfatório, o "pré-produto" deve ser descartado ou alterado de forma que o retorno seja aceitável.

\subsection{Estruturantes Jurídicas}

De conformidade com o Direito Concorrencial, a fixação do preço deve ser legitimamente feita a partir da estrutura de custos. O uso de política de preços predatórios é delicado, ainda mais se puder ser comprovada a intenção direta de afastar concorrente. As regras antitruste pró́bem os preços abusivos. Importa aqui o conceito de função social da propriedade empresarial e do contrato. Os valores, princípios e regras jurídicas constitucionais e concorrenciais restritivas do abuso do poder econômico são os elementos estruturantes deste sistema ambiental.

\subsection{Ambiente Científico-Tecnológico}

Este ambiente é das interações do "pré-produto" com as oportunidades, viabilidades, ameaças e bloqueios relativos à tecnologia ligada a ele, à disponibilidade dessas tecnologias no Brasil e no resto do mundo, entradas de patentes no domínio público livres para uso, pesquisas básicas que estejam sendo desenvolvidas por universidades e entidades de pesquisa no Brasil e no mundo. O "pré-produto", para ser adequado a esse ambiente, deve representar um aproveitamento de oportunidade quanto a uma dada tecnologia. Se não houver segurança quanto à tecnologia, se isso for uma barreira, restrição ou ameaça, a segurança tecnológica deve ser obtida por outra fonte, com alteração do "pré-produto", ou o seu descarte imediato ser considerado.

\section{5. i Estruturantes Jurídicas}

Os bens intangíveis, tecnológicos e autorais são, em regra, objeto de propriedade; excepcionalmente não o são. Impõe-se, assim, a investigação jurídica quanto à sua utilização no “pré-produto”. Os valores, princípios e regras jurídicas de propriedade industrial, de direito autoral e de propriedade intelectual em geral são os elementos estruturantes deste sistema ambiental. 


\subsection{Ambiente Concorrencial}

Este ambiente é o das interações do "pré-produto" com as oportunidades, viabilidades, ameaças e bloqueios apresentados pelos concorrentes existentes ou possíveis por conta do "pré-produto". O passo importante será verificar quem são esses concorrentes e suas condições de criação de bloqueios e ameaças ao "pré-produto". Pode ocorrer de o comportamento dos concorrentes oportunizá-lo. Caso o "pré-produto" não consiga diferenciar-se dos concorrentes, no valor líquido que aporte, será o caso de reformulá-lo ou abandoná-lo. A avaliação dos concorrentes também deve se dirigir às análises comparativas de redes de distribuição e entrega do "pré-produto".

Os concorrentes relevantes são os seguintes, em que seguimos Porter (1980):

- os que já estão na mesma indústria do "pré-produto";

- os possíveis entrantes vindos de outros mercados relevantes que tenham facilidade de custos ou de ganho sinergético que motive objetivamente a apresentação de produto ou serviço que concorra com o "pré-produto";

- os vindos de outros mercados relevantes em que já ofereçam produtos que possam ser identificados como substitutos do "pré-produto"; e

- os fornecedores ou compradores de insumos para quem uma integração para frente ou para trás, na forma de produto ou serviço concorrente do "pré-produto”, seja vantajosa; e

- os grupos de empresas de alta diversificação, para quem o investimento em produto ou serviço concorrente do "pré-produto" seja uma alternativa valiosa.

4.6. i Estruturantes Jurídicas

As relações com os concorrentes devem ser legitimadas pelo crivo do Direito Concorrencial Público e pelo que chamamos de Direito Concorrencial Privado (CARVALHO, 2002), no que se incluem as questões cíveis de responsabilidade civil concorrencial, cobrindo-se inclusive as de concorrência desleal. Os valores, princípios e regras jurídicas constitucionais econômicas e concorrenciais são os elementos estruturantes deste sistema ambiental.

\subsection{Ambiente do Consumidor}

É o ambiente das interações do "pré-produto" com as oportunidades, viabilidades, ameaças e bloqueios apresentados pela legislação de Direito do Consumidor e pela jurisprudência dos juizados especiais cíveis e órgãos de defesa do consumidor em geral, relativos a ofertas semelhantes ou intercambiáveis com o "pré-produto". Inclui também o exame dos procedimentos de segurança do "pré-produto" quanto aos danos que possa causar ao consumidor, levando em conta as várias possibilidades de seu uso ou consumo. Caso o "pré-produto" não possa atender ao consumidor, o que abrange os referidos cuidados de segurança, ele deve ser alterado ou descartado de vez. 


\section{7. i Estruturantes Jurídicas}

As relações com o consumidor são objeto do Direito Constitucional e do Direito do Consumidor. Os ambientes operacionais concorrencial e do consumidor têm uma alta articulação, no entanto, devem ser tratados em separado, como tivemos oportunidade de apreciar em trabalho anterior (CARVALHO, 2004). Os valores, princípios e regras jurídicas de proteção do consumidor são os elementos estruturantes deste sistema ambiental.

Esses são os sete ambientes em que se devem fazer investigações pontuais. O oitavo ambiente, denominado ambiente espaço-tempo, em que foi dada consistência aos sete primeiros, é assunto para mais adiante.

\section{PERGUNTAS SOBRE OS AMBIENTES}

O método que sugerimos pode ser chamado de "maiêutico de implicação interativa", com fundamento em Sócrates, no século IV a.C. "Maiêutico", do grego maieutikos, porque age como parteira, extraindo idéias e informações a partir de perguntas. A imagem é de que as idéias já existem na mente 'grávida' do investigador, mas precisam de um parto para que se tornem manifestas. "De implicação interativa”, pelo fato de as perguntas terem por fundamento a tensão interativa entre dois elementos. Um, o "pré-produto", o qual se quer modelar e dar condições de sucesso; outro, cada segmento de ambiente em que será posto ao ser lançado.

Em nosso plano metodológico, cada aspecto ambiental será perante o "pré-produto": uma oportunidade, uma viabilidade, uma ameaça ou um bloqueio. A mente do advogado é "engravidada" com a tensão contida na pergunta para, em seguida, colher-se a resposta. Evidentemente, para que seja possível uma resposta consistente e útil, é preciso que o advogado tenha informações suficientes sobre o aspecto ambiental dado, além de conhecer com exatidão o "pré-produto". E mais, como já dito, tenha atitude transdisciplinar, competência de "interface” e boa cultura geral.

Com base na nossa experiência profissional, cabem perguntas a serem feitas e respondidas com os olhos postos na modelagem do "pré-produto". Trata-se de perguntas para provocar percepções e conhecer melhor o que se quer e modelar o "pré-produto" da melhor maneira. É um processo criativo, uma vez que o "pré-produto" é algo "inexistente" no real; trata-se de um esforço intelectual de superação. Nesse quadro, deve-se estar atento para perceber bloqueios e ameaças ao "pré-produto", diante dos quais a conduta profissional é encontrar uma possibilidade alternativa para o "pré-produto", que o leve a uma situação de oportunidade, ou ao menos de viabilidade. Convida-se o advogado organizacional a não praticar a argumentação do sim e do não, do pode e do não pode, do certo/errado, do verdadeiro/falso, etc. Há assim, sugerimos, dois momentos de exercício intelectual. No primeiro, procura-se perceber o que parece ser bloqueio ou ameaça ao 
“pré-produto” como esse 'existir' naquele momento. No segundo, devem-se buscar exclusivamente as possibilidades positivas para o "pré-produto", isto é, de como ele pode - feitas alterações no "pré-produto" ou no próprio ambiente, ou não - ter viabilidade ou mesmo oportunidade virtuosa. Como ensina De Bono (1999), não se deve proceder aos dois exercícios ao mesmo tempo, como que sopesando os fatores. Ocorre que a bioquímica mental não é a mesma, para criticar e imaginar possibilidades novas e criativas. Além disso, a tendência seria em favor de precaução, de dizer não ou ceder ao bloqueio ou à ameaça e regredir esterilmente.

As alterações poderão ser feitas no "pré-produto" ou no próprio ambiente. Mudanças no "pré-produto" podem ocorrer na sua aparência, na sua fórmula ou elementos componentes, nos seus propósitos declarados de atendimento a necessidades-desejos dos consumidores, no seu preço e na oferta de diferenciações, na sua identidade própria em contraste com os produtos concorrentes, etc. As mudanças ambientais são resultado de intervenções da organização empresarial para viabilização ou oportunização do "pré-produto", como uma matéria jornalística sobre os pontos favoráveis de um elemento do "pré-produto", uma mudança de legislação por lobbying, a compra de direitos de patente relativa ao "pré-produto", ações perante concorrentes em cartel, instalação de uma nova fábrica especializada no "pré-produto", etc.

As perguntas servem como provocações para chegar-se à percepção de como o novo produto decorrente do "pré-produto" deve ser. As perguntas podem e devem remeter a outras indagações e a respostas que podem não estar no âmbito das respostas articuladas para "aquela" pergunta. O advogado deve estar atento a todas. Nada a temer em ele próprio fazer essas perguntas no âmbito do grupo do projeto do "pré-produto" ou perante os gerentes ou especialistas que as possam responder. Ele terá autoridade para tanto, uma vez que as poderosas estruturantes jurídicas existentes em todos os ambientes validarão a pertinência da participação ativa do profissional jurídico.

É atribuição do gestor a definição do grupo que desenvolverá o "pré-produto". O gestor provavelmente convocará, com o advogado, profissionais de marketing, de produção e logística, de controle e de finanças; talvez ainda outros.

Para melhor entendimento da metodologia do "pré-produto" como apresentada neste trabalho, convém que ela seja usada em exercício prático de simulação até chegar a um "projeto executivo". Recomendamos que o leitor primeiro saiba o que deve conter o projeto executivo quanto a conteúdo, de modo que saiba a que deve chegar e com que dados. Em seguida, volte a este ponto, em que nos está lendo, para fazer as perguntas quanto aos ambientes, percebendo que as perguntas servem para dirigir a sua atenção a determinados pontos de interesse do "pré-produto". O leitor pode usar, para esse exercício, uma experiência própria com projetos de novos produtos, como advogado. Não importa que sua participação real na ocasião 
tenha sido pequena, em razão de bloqueios por parte da cultura da empresa ou dos seus gestores, que não quiseram o advogado envolvido, mesmo que ele estivesse disponível e capacitado.

Quando agora for realizado o exercício, o leitor perceberá a importância que teria tido para a qualidade do "pré-produto".

Lembramos que as perguntas são chamadas da sua atenção para determinados pontos. Muitas vezes, as perguntas não serão diretamente pertinentes ao seu "préproduto", mas provocarão algum tipo de ponderação útil. Nada importa ou é mesmo adequado que de um ponto a atenção do leitor flua para outro foco. O que é relevante é o escrutínio de todos os aspectos possíveis, inclusive aqueles escondidos nos recônditos dos ambientes.

\section{I Perguntas sobre o Ambiente Jurídico-Político}

Como está o "pré-produto" (como percebido agora nesta fase do projeto) em interação com:

a) o cumprimento ou aproveitamento da legislação administrativa e tributária?

b) o cumprimento ou aproveitamento da legislação trabalhista e de higiene/segurança?

c) os projetos em curso no Congresso Nacional e outras casas legislativas?

d) as licenças e autorizações de governos e agências públicas?

e) o cumprimento da legislação do meio ambiente e de saúde pública?

f) as providências relativas a posturas municipais?

\subsection{Perguntas sobre o Ambiente Interno}

Como está o "pré-produto" (como percebido agora nesta fase do projeto) em interação com:

a) os outros "pré-produtos" e produtos em produção?

b) os recursos orçamentários?

c) os recursos humanos necessários?

d) os meios industriais para sua produção e entrega?

e) os meios de informação, controladoria e sistemas integrados corporativos?

f) os modelos contratuais e formulários relativos a comercialização e vendas?

g) as providências jurídico-societárias necessárias para sua aprovação?

\subsection{Perguntas sobre o Ambiente Cultural}

Como está o "pré-produto" (como percebido agora nesta fase do projeto) em interação com:

a) os valores culturais de conforto, segurança, beleza, prestígio social, etc.?

b) os valores religiosos e costumes recomendados pelos preceitos de religiões?

c) os preceitos de estética disseminados na comunidade e no mercado-alvo?

d) o que seja entendido como "politicamente correto"? 
e) o pensamento e o julgamento das pessoas formadoras de opinião?

f) as necessidades-desejos que o "pré-produto" supõe estar satisfazendo?

\subsection{Perguntas sobre o Ambiente Socioeconômico}

Como está o "pré-produto" (como percebido agora nesta fase do projeto) em interação com:
a) o seu suposto ou assumido mercado-alvo ou segmento mercadológico?
b) estudos de renda e demográficos do mercado-alvo?
c) as possibilidades de seu desenvolvimento em novas ofertas/segmentos?
d) as possibilidades de uma família de produtos?
e) a política de preços?

\subsection{Perguntas sobre o Ambiente Científico-Tecnológico}

Como está o "pré-produto" (como percebido agora nesta fase do projeto) em interação com:

a) o estado da tecnologia disponível?

b) a possibilidade de uso indevido de direitos imateriais de outros?

c) a garantia de suprimento de tecnologia e de upgradings?

d) as possibilidades da sua proteção como segredo de negócio?

e) as patentes de terceiros que estejam para tornar-se de domínio público?

f) a garantia da provisão de conhecimento científico e tecnológico?

\subsection{Perguntas sobre o Ambiente Concorrencial}

Como está o "pré-produto" (como percebido agora nesta fase do projeto) em interação com:

a) a sua inserção no(s) mercado(s) relevante(s)?

b) os planos e metas relativos aos produtos concorrentes?

c) o patrimônio e a capacidade de endividamento dos concorrentes?

d) os fornecedores de insumos próprios e os dos produtos concorrentes?

e) a força das marcas e as insígnias próprias e dos produtos concorrentes?

f) a contratação de agentes e de distribuidores?

\subsection{Perguntas sobre o Ambiente do Consumidor}

Como está o "pré-produto" (como percebido agora nesta fase do projeto) em interação com:

a) as instruções ou manuais de uso e/ou consumo?

b) a transparência das informações veiculas pela ações de publicidade?

c) os registros de pesquisa e procedimentos quanto à qualidade e à segurança?

d) o equilíbrio contratual e a não-abusividade dos contratos de comercialização?

e) as garantias dadas nos textos de comercialização? 
f) a devolução em caso de defeitos e trocas em caso de arrependimento?

g) as peças sobressalentes e a assistência técnica?

\section{O AMBIENTE ESPAÇO-TEMPO}

O ambiente espaço-tempo corresponde a todos os demais ambientes vistos em uma perspectiva de evolução temporal e de movimento. Isto é, das oportunidades, viabilidades, ameaças e bloqueios proporcionados pelo fato de os elementos ambientais evoluírem no espaço-tempo de forma a que percam sua atual importância oportunizadora ou restritiva do "Pré-Produto". A expressão "espaço-tempo", que aproveitamos de Koch (2003, p.170-186), visa indicar, em memória à "teoria da relatividade” de Albert Einstein, que também, nos planos social e cultural, o tempo não é um contínuo ou um fluxo constante, mas, sim, interdependente do espaço para se avaliar a oportunística do "pré-produto". Em suma: o tempo poderá ser mais ou menos "rápido" conforme os acontecimentos no espaço tiverem seqüência mais ou menos curta. Isso não é filosofia. É da experiência comum que os eventos se aceleram ou se espaçam, fazendo com que seja absurdo para o estrategista supor, no tocante aos seus estudos de oportunidade ou oportunística, um tempo de fluxo constante. É no espaço-tempo que podem ser encontrados os nichos para a melhor ocasião de o "pré-produto" transformar-se em novo produto posto no mercado ou, então, de perder a oportunidade ou mesmo a viabilidade. Outra visão qualquer seria empobrecedora. A realidade ambiental é melhor reproduzida com a inclusão da dimensão espaço-tempo.

\section{ESTUDO DOS DADOS E PROJETO EXECUTIVO}

Ao final, ter-se-á um amontoado de anotações relacionadas às provocações indagativas feitas. O que fazer? Entendemos que as respostas fundamentadas às questões deverão ser classificadas como oportunidades, viabilidades, ameaças ou bloqueio ao "pré-produto". Depois disso, cabe ponderar se o resultado do "pré-produto" em cada ambiente tende a ser positivo. Se a tendência for positiva, o que poderá não resultar do maior número de oportunidades registradas, mas da qualidade e peso de certas oportunidades, então caberá repensar o "pré-produto" perante todas as ameaças e bloqueios identificados de modo a verificar se não seriam possíveis alterações no "pré-produto" que o levarão ao menos a neutralizar as ameaças e bloqueios, sem que se percam as adaptações do "pré-produto" que o fizeram ter respostas de oportunidade.

Feito isso, cumpre juntar o trabalho produzido em cada ambiente e discutir cada "pré-produto"/ambiente diante de cada um e dos demais seis "préprodutos"/ambientes em conjunto. Certamente, haverá "pré-produtos" diferentes, 
uma vez que, em cada ambiente, se fez o exercício de adaptação de "pré-produto" para transformar as situações de ameaça e bloqueio em oportunidade ou, ao menos, em viabilidade.

O exercício de busca da melhor modelagem do "pré-produto" é um empreendimento do grupo do projeto com a ativa participação do advogado. É ser um processo de idas e voltas, de conflitos e encontros, nunca algo linear ou cartesiano. O processo do novo produto é essencialmente criativo. O "pré-produto" na sua forma final decorrerá mais de insights que de esforço analítico ou do relacionamento de informações no computador (DE BONO, 1991, p. 217-219). É ainda um processo social em que o cometimento de cada representante do grupo do projeto deve ser pleno e leal tanto no processamento das idéias como no criticismo destas. Não há situação de perde-ganha ou de certo-errado, mas o sentido construtivo do achamento do mais adequado "pré-produto".

Cabe perguntar se o uso do projeto de outro modelo metodológico pelo grupo teria algum impacto, sabendo-se que as grandes corporações têm cada uma os seus procedimentos. Assumimos que, ocorrendo isso (o que é comum), não significará que o advogado organizacional deva valer-se ou limitar-se aos procedimentos corporativos mandatórios. Cumpre, ao que parece, que o advogado tome como instrumental profissional seu o modelo dos ambientes sob estruturantes jurídicas ou outro que corresponda a uma rationale de investigação jurídica. Será a partir de um modelo profissional próprio de atuação que o advogado poderá firmar convicção e terá argumentação para o cumprimento de seu mister de garantir ao "pré-produto" a melhor qualidade jurídica.

Para o projeto executivo (o qual também deve ser um instrumental do advogado, independentemente do documento usado pelo grupo), é preciso atender, pensamos, aos seguintes títulos e segmentos. A descrição de projeto executivo a seguir é uma montagem a partir do que vimos em empresas de cosmética, da indústria farmacêutica, da indústria bélica e do setor bancário e securitário:

- descrição do produto; descrição do produto conforme sua percepção pelos consumidores; premissas e projetos de marketing e publicidade em sustentação do produto; marcas, patentes e outros registros proprietários; possibilidades de diferenciações do produto; identificação por exclusão de produtos semelhantes, etc.;

- $\quad$ estrutura gerencial e de recursos humanos com descrição de responsabilidades e competências, interfaciamentos e reportes específicos quanto à dinâmica da produção e entrega; níveis de autoridade para aprovação de "desvios"; inclusão do produto em sistema integrado de gestão - information integrated system;

- base física e maquinário para produção e entrega do produto; fornecimentos necessários do produto por terceiros; insumos financeiros para produção e entrega do produto; pós-venda e assistência técnica; garantias e suporte ao consumidor; 
- parceiros nos procedimentos de produção e de entrega (descrever, se for o caso, o entrosamento do produto com adições de ofertas de parceiros, quando de blocos de ofertas integradas);

- política de comercialização e de preços; critérios de revisão das premissas; procedimentos contratuais de venda do produto e "desvios" possíveis; modelos de contratos e documentos outros de sustentação da comercialização do produto;

- definição de expectativas comerciais e retorno; mecanismos de monitoramento do desempenho do produto e critérios para avaliação de performance; definição da periodicidade de reuniões de monitoramento e pessoas envolvidas;

- discussão da oportunística do espaço-tempo para o produto; cronograma de procedimentos, ações e interdependência desses eventos; critérios e periodicidade de revisão do cronograma; e

- planos de contingência (descrever as alternativas a terceiros de venda de todo o empreendimento relativo ao produto, identificação de compradores possíveis, identificação de oportunidades de parceirização com terceiros na divisão dos riscos).

O projeto executivo e a documentação relativa ao "pré-produto" devem ser percebidos como "informação confidencial” proprietária em conformidade com os preceitos protetivos de Direito Comercial e da Propriedade Industrial (ver FEKETE, 2003, sobre o regime proprietário dos segredos de negócio e informações confidenciais). Representam um esforço formidável na produção de conhecimento novo aplicado empresarialmente (como se estuda, na Teoria das Organizações, em NONAKA; HIROTAKA, 1997; STEWART, 1998; CHOO, 1998; EDVINSSON, 2003; KROGH et al., 2000). Aconselhamos, de modo a preservar a propriedade sobre o conhecimento gerado, que se separe da referida documentação, para efeito do Direito do Consumidor, a memória dos cuidados relativos à segurança do novo produto quanto ao seu uso ou consumo.

\section{CONCLUSÃO}

Podemos concluir em caráter eminentemente provocativo:

(i) O envolvimento e a participação do advogado em projetos de novos produtos são mandatórios. A participação do advogado não é um traço cultural norte-americano que chegou há décadas ao Brasil, mas impõe-se em todos os projetos de novos produtos como ponto central e inafastável. Cumpre que os advogados organizacionais internos e os vindos de escritórios desenvolvam suas competências de "interface" com outros especialistas, bem como aumentem sua percepção transdisciplinar e seu letramento funcional nos assuntos de organização e economia.

(ii) Uma metodologia para o uso do advogado com intuito de melhorar os projetos de novos produtos é proceder à verificação das "interações" do "pré-produto" 
com os diversos segmentos de ambiente, vistos a partir de suas estruturantes jurídicas, valores, princípios e regras de ordem normativa que determinam a cognição sobre cada ambiente, ou, ainda, em uma ótica mais simples, estabelecem critérios estáveis e de aceitação geral para o entendimento dos ambientes.

: ARTIGO APROVADO (12/09/2007) : RECEBIDO EM 11/04/2007

\section{REFERÊNCIAS BIBLIOGRÁFICAS}

BERTALANFFY, Ludwig von. General system theory. New York: George Braziller, 2001.

CARVALHO, Gilberto de Abreu Sodré. Responsabilidade civil concorrencial: introdução ao direito concorrencial privado. Rio de Janeiro: Lumen Juris, 2002.

. A nova empresa na era da concorrência e da gestão do conhecimento. Rio de Janeiro: Editora FGV, 2003.

- Concorrência e consumidor no âmbito da administração pública; uma relação a ser vista como

de tensão no plano dos valores. Revista de Administração Pública - RAP, v. 38, n. 4, , p. 643-655, jul.-ago. 2004.

—- CAVALCANTI, Bianor Scelza. Esboço sobre a transdisciplinaridade como método possível: a superação da co-responsabilidade dos consorciados nas licitações e o caso das PPPs. Revista de Direito Administrativo - RDA, v. 244, p. 151-164, jan.-abr. 2007.

CHOO, Chun Wei. The knowing organization: how organizations use information to construct meaning, create knowledge and make decisions. New York: Oxford University Press, 1998.

COOPER, Robert Gravlin. Winning at new products: accelerating from idea to launch. 3. ed. Cambridge: Basic Books, 2001.

DE BONO, Edward. I am Right, You are wrong: from this to the new renaissance: from rock logic to water logic. Penguin Books, 1991.

. Serious creativity: using the power of lateral thinking to create new ideas. New York: Harper Business, 1992. Six thinking hats. Boston: Back Bay Books, 1999.

DOMINGUES, Ivan. Em busca do método. In:- (Coord.). Conhecimento e transdiciplinaridade II - aspectos metodológicos. Belo Horizonte: Editora UFMG, 2005. p. 17-40.

DRUCKER, Peter. Sociedade pós-capitalista. São Paulo: Pioneira, 1993.

EDVINSSON, Leif. Longitude corporativa: navegando na economia do conhecimento. São Paulo: Makron Books, 2003. FEKETE, Elisabeth Kasznar. O regime jurídico do segredo de indústria e comércio no direito brasileiro. Rio de Janeiro: Forense, 2003.

FERRAZ JUNIOR, Tercio Sampaio. Introdução ao estudo do direito: técnica, decisão, dominação. 3. ed. São Paulo: Atlas, 2001.

KOCH, Richard. As leis do poder: a ciência do sucesso. Rio de Janeiro: Rocco, 2003.

KROGH, Georg von; ICHIJO, Kazuo; NONAKA, Ikujiro. Enabling knowledge creation: how to unlock the mystery of tacit knowledge and release the power of innovation. New York: Oxford University Press, 2000.

KUHN, Thomas S. A estrutura das revoluções cientificas. 8. ed. São Paulo: Perspectiva, 2003.

LAWRENCE, Paul; LORSCH, Jay. Organization and environment. [S.l.]: Harvard Business School Press, 1967. LEÃES, Luiz Gastão Paes de Barros. A responsabilidade do fabricante pelo fato do produto. São Paulo: Saraiva, 1987. MORGAN, Gareth. Imagens da organização. Edição Executiva. São Paulo: Atlas, 2002.

NICOLESCU, Basarab. O manifesto da transdisciplinaridade. Tradução de Lucia Pereira de Souza. 2. ed. São Paulo: Triom, 2001.

NONAKA, Ikujiro; HIROTAKA, Takeuchi. Criação de conhecimento na empresa. Rio de Janeiro: Campus, 1997. 
PORTER, Michael E. Competitive strategy: techniques for analysing industries and competitors. New York: Free Press, 1980.

SANTOS, Fernando Gherardini. O direito de marketing: uma abordagem jurídica do marketing empresarial. São Paulo: RT, 2000.

STEWART, Thomas A. Capital intelectual: a nova vantagem competitiva das empresas. Rio de Janeiro: Campus, 1998. THOMPSON, Arthur A.; STRICKLAND, A., J. Planejamento estratégico: elaboração, implementação e execução. São Paulo: Pioneira, 2002.

URBAN, Glen; HAUSER, John. Design and marketing of new products. Prentice Hall, 1993.

\section{Gilberto de Abreu Sodré Carvalho}

Gilberto Sodré Advocacia Rua Machado Bittencourt, 317, cj. 81 Vila Clementino - 04044-000 São Paulo, Brasil gsodrelagilbertosodre.com.br
MESTRE EM DIREITO POLÍtico E ECONÔMICO PElo MackenzIe, Brasil Advogado 